\title{
DIGITALIZATION OF EDUCATION: PEDAGOGCIAL PRIORITIES
}

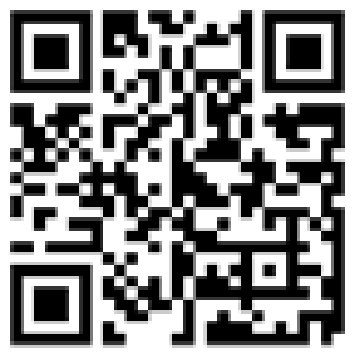

To cite this article:

\author{
Svitlana Sysoieva, Dr. Sc., Prof. \\ Academician-Secretary, \\ Department of General Pedagogy and Philosophy of Education, \\ National Academy of Educational Sciences of Ukraine, \\ Kyiv, Ukraine \\ 2099823@gmail.com \\ https://orcid.org/0000-0003-2499-732X
}

Sysoieva, S. (2021). Digitalization of education: pedagogical priorities. Education: Modern Discourses, (4), 14-22.

https://doi.org/10.37472/2617-3107-2021-4-02

\begin{abstract}
The paper analyses the impact of globalization and technological development of society on scientific activity, education system, organization and technologies of the educational process; pedagogical priorities of digitalization of education are identified: joining the efforts of scientists and practitioners for a comprehensive analysis and interdisciplinary solutions of modern problems of digital educational environment, pedagogical principles of digitalization of education; formulation of conceptual provisions of digital pedagogy and definition of the basic pedagogical concepts of digital education, development of digital didactics, revision of forms, methods, means and technologies of teaching, education and development of the learner in digital space; identification of features and directions of education of children and youth in the digital environment, new forms and approaches to organizing the educational impact on children and youth in the digital environment, outlining the risks of digitalization of education and means of overcoming them; it is shown that the mission of modern education is to provide society and every citizen with a transition to a digital age focusing on different tools, different living environment and training not only young people but also middle-aged and older people for new types and kinds of work.
\end{abstract}

Keywords: digital didactics; digital pedagogy; digitalization of education; education in digital environment; pedagogical priorities, risks of digitalization of education.

\section{INTRODUCTION}

The processes of globalization and informatization of the society have significantly affected the technology of scientific activity, education system, organization, and technology of the educational process. The concept of "informatization of education" has been understood as a set of measures for the transformation of pedagogical processes based on the introduction of information products, tools, technologies into teaching and education (Nikulina \& Starichenko, 2018, p. 108). Many Ukrainian scholars have contributed to the research into the issues of introduction of information technologies in the educational process, in particular: R. Gurevich, O. Spirin, N. Morse, V. Bykov, B. Lapinsky, V. Kovalchuk, and others (Kovalchuk \& Podolskaya, 2018, p. 523).

Informatization of education has caused the emergence of such concerns in educational practice as ensuring academic integrity, autonomy of universities, the organization of 
international project activities, etc. In pedagogical science, considerable attention was given to the issues of the informatization of education, the use of information and communication technologies, developing information, information and communication competency of educators and other professionals.

Educational researchers and practitioners seem to be readjusting and adapting to the new realities of civilization. At the same time, the problems facing education during the COVID-19 pandemic, a phenomenon that no one could have predicted, came as a shock to educators and forced the teaching community to act quickly and creatively within this uncertainty. The situation with COVID-19 can be considered the "black swan situation, with the logic that makes the unknown event much more important than the one you know about. Black swans came into the world and shocked it just because no one expected them" (Taleb, 2019, p. 16).

The events of the pandemic have clearly shown that in the modern world there is a change of civilizations, the transition to a new level of civilizational development, which is caused by a technological breakthrough - digitalization, big data, and technologies based on them. Today it is argued that it is appropriate not to talk about different approaches to informatization and digitalization, but about a single end-to-end process of transforming society, based on evolving technologies, and the change of their generations determines the stages of human development, which included informatization stage that is currently changing to digitalization.

Gradually, the generally accepted terms "globalization" and "informatization" began to be used with the term "digitalization" or replaced by it. Society began to talk about the digital economy, digitalization of production, agriculture, education, social sphere and others. The complexity and systematization of attention to digitalization at all levels of society allows us to draw conclusions about the extent of the impact of this process on all spheres of social relations. In the field of education, these changes occur at the level of space and time, the ontology of the education system itself is changing. Digitalization is becoming a mainstream in the development of education (Zenkov, 2020, p. 54), because the education system, according to many scholars, should ensure a rapid transit for the society and every citizen a digital age that is focused on different tools, living environment and prepare not only young people but also middle-aged and older people for new types and kinds of work.

Therefore, the attention of scientists and practitioners today is focused on the problems of digitalization of education, the educational process, the organization of professional training in the digital environment.

\section{Digitalization in education: a new paradigm of thinking, communication and interaction.}

The ideas of digitalization of education were considered by scientists and practitioners before the crisis caused by the COVID-19 pandemic.

The essence of this term and its role in the civilizational development of society is interpreted by scientists in different ways, in particular, as "the era of big data and technologies based on them; a new paradigm of thinking, communication, interaction with each other; a new stage of development of society aimed at improving the quality of life; a tool for improving business processes and comprehensive solutions to problems of infrastructural, managerial, behavioral and cultural nature" (Strekalova, 2019, p. 86).

The digitalization of education contributes to the development of the individual trajectory of students, management of their own learning outcomes, overcoming the psychological barriers of traditional learning.

The process of digitalization of education involves "transformation into digital format all teaching materials and creation of public knowledge bases based on them, maximum 
transformation of the educational process into a global network and use for learning mobile and cloud technologies, application of intelligent systems for educational process management, wide implementation of open training courses" (Strekalova, 2019, p. 86).

However, the problem of digital transformation of education and the educational process, in our opinion, is much deeper and unpredictable in terms of its consequences and is exacerbated by the fact that, objectively, we cannot influence the civilizational development of humanity, technological progress and further technology. Nor can we deny the fact that the modern child is born with a smartphone in hand," and that teachers, and educators are generally less competent in digital processes than students.

One of the most important problems of digitalization of education is that innovations in the digital educational environment are not only technical and technological innovations, but also changes in the content and organization of educational content, in the structure and organizational principles of educational institutions. This requires a revision of the conceptual provisions, the content of categories and concepts of established pedagogical science, their adaptation (or development of new content) to the digital educational space.

That is why the formation of digital competence of teachers, educators, students of all levels, as "the readiness of educational institutions for training digital society requires not only further technical and technological modernization of education, but also training (retraining) teachers, in particular in terms of developing digital literacy, the developing the ability to digitize teaching materials, use them in pedagogical practice, develop electronic textbooks with elements of interactive technology and programmed learning, create massive open educational courses and teach online and/or in a blended format, including effective communication skills" (Strekalova, 2019, p. 87).

The process of digitalization of education and any other spheres of human life involves the formation of each person's digital (information) culture for the competent use of created opportunities, and integral integration into the digital (information) society.

When working in the digital educational environment, the following risks of digitalization of the educational process cannot be ignored:

- loss of basic cognitive skills (ability to read, count, write), reduced quality of education;

- "public" model of the educators and teachers, high requirements to their psychological qualities, conflicts growth;

- reduction of personal contacts, talented youth and teachers outflow abroad, reduction of the general level of training, problems with quality assurance;

- changes of the training content requirements, further change of the training tools;

- changing the requirements for the qualification of specialists, reducing the need for "intellectual" specialists and "attraction" to its technological image, reducing the contingent of higher education;

- moving towards "educational services", departure from the fundamental approaches, change/redistribution of the functions of the higher education institutions administration and educators, growth of conflicts, reduction of the quality of education;

- loss of the status of the domestic higher education, reduction of the student body (Strekalova, 2019, p. 87).

A significant disadvantage of online education is also its focus on meeting short-term or, at best, medium-term goals.

A specialist who has mastered a limited amount of knowledge and has not received a basic fundamental training, can only count on intellectual "superstructures", the stability of which is illusory (Zenkov, 2020, p. 54).

In the digital transformation of the educational process, in our opinion, it is important to preserve the fundamentality of the classical education system, because creative productive 
human activity requires not only digital skills, but also fundamental knowledge, critical thinking, developed creativity (Sysoieva, 2014).

It can be agreed that ensuring the quality of education, in particular higher education, and preventing possible negative changes requires pedagogical research, in particular, in the following areas: the model of digital education teacher/educator, the content of their training; techniques for developing digital educational content, assessment methodology and its quality and application in the educational process, taking into account ergonomic, valeological, psychological and pedagogical requirements; effective methods, forms, tools for teaching in the open educational environment and their methodological grounds, in particular the ratio of traditional and e-learning, contact and independent students' work, methodology for student's progress monitoring and achieving learning outcomes in terms of transferring the learning process to the global network; means for ensuring the quality of education, prevention of possible risks in the context of digitalization of education, etc. (Strekalova, 2019, p. 88).

One of the most significant positive features of digitalization of education is the expansion of educational and research scope, the ability to diversify teaching forms and methods, aimed at the students' needs taking into account the requirements and demands of the labour market. At large enterprises, the practices of creating corporate universities, their own professional development centres and training programmes is increasingly common thing (Zenkov, 2020, p. 53). Thus, formulated in the twentieth century, the concept of lifelong learning in the context of globalization is becoming important for everyone.

The development of digital educational technologies contributes to the transformation of the model of the educational process organization (from the education for all to the education for everyone approach), allows to develop individual educational trajectories for students, take into account their pace, interests, and characteristics.

Modern human interaction in the digital space is different from the interaction of the past. This is directly related to targeted innovations at the technological level: expanding the scope of digital solutions and services, the availability of gadgets, the intensive development of social media. Naturally, all this affects the change of style of interpersonal and communicative interaction of people of any age. There is an unequivocal opinion that the presence of modern competence of modern man is a prerequisite for a comfortable existence in society, and its formation is one of the most important tasks of the education system.

Thus, in the context of digitalization of education, we consider it urgent to address the following important issues that determine the pedagogical priorities of digitalization of education: 1) Why is it important today to unite the efforts of scientists and practitioners to solve pedagogical problems of digitalization of education? 2) How does the essence of the conceptual provisions and the content of the basic pedagogical concepts that create the foundation of pedagogical science change? In other words, what is digital pedagogy? 3) How to solve the problem of raising children and youth in the digital space?

\section{Advisory Council on Digital Education and Pedagogy.}

Exploring the issues of digitalization of education requires engaging scientists into the interdisciplinary activities. In order to join the efforts of scientists and practitioners in solving pedagogical problems of digitalization of education, the Advisory Council on Digital Education and Pedagogy at the Department of General Pedagogy and Philosophy of Education of the National Academy of Educational Sciences of Ukraine created was created and is a collegial association of members of the Department, all interested scientists and practitioners.

The purpose of the Council is to unite the efforts of scientists and practitioners to study 
current issues (philosophical, theoretical, methodological, practical) of development the digital education and pedagogy in Ukraine in accordance with state policy objectives, including the National Economic Strategy 2030, as well as in-depth research with a broad public discussion of the benefits and threats of digitalization of educational and scientific activities, developing analytical conclusions and recommendations for the management of education.

The main activities of the Council include:

- studying domestic and foreign experience of digitalization of education in response to modern challenges, innovative technologies of digital education development;

- exploring the basic principles of development of the modern information world, that is featured by the digitization, visualization, virtualization of all aspects of life;

- identification of systemic factors in the development of digital education and pedagogy in Ukraine;

- exploring students' attitudes towards introduction of remote and blended learning technologies;

- research into the transformation of essence and content of the didactic and pedagogical principles of the educational process organization in the conditions of digitalization of education;

- contributing to the creation of a common digital platform for preschool education;

- remote advisory to parents and educators on the education of children of early and preschool age;

- designing conceptual framework and methodology of education for children and youth in the digital environment;

- exploring project management processes of transformation of domestic higher education institutions into digital universities;

- developing a strategy for the development of digital competence of research, research and pedagogical, pedagogical staff;

- promoting introduction of training courses (seminars, webinars) on digital education and pedagogy for research, research and pedagogical, pedagogical staff of educational institutions;

- collecting independent sources of statistical information on digitalization of education and preparing analytical conclusions;

- conducting other research that contributes to the study of issues of digital education and pedagogy in Ukraine.

To ensure collegiality, the balance and scientific credibility in decision-making and preparation of analytical materials, an expert commission of the Council is created, which includes (by consent) well-known scientists, research and pedagogical staff, employees of the NAES of Ukraine, teachers who have equal voting rights. The experts' recommendations are subject to the collegial decisions of the Council.

It should be noted that the Council in its activities interacts with educational institutions of all levels and types, research institutions and structural units of the NAES of Ukraine, public authorities and local governments, and NGOs.

\section{Digital pedagogy: a component of pedagogy or a separate branch of pedagogical science?}

Modern society is evolving in the direction of digitalization, and therefore there is an urgent need to change the pedagogical paradigm, rethink the essence of pedagogical technology, forms and methods of teaching, education and development of children and youth and older people to adapt to the digital world. To organize the educational process in the digital space, 
such concepts as: "pedagogical skills", "pedagogical creativity", "pedagogical interaction", "pedagogical communication", "subject-subject interaction", etc. need to be clarified.

One of the leading tasks is to create a modern theory of education in the context of digitalization of education, which will be able to overcome the limitations of traditional pedagogy. Digital technologies in the modern world are not only a tool, but also an environment that opens new opportunities for learning at a convenient time, lifelong education, designing an individual educational trajectory, transforming users of electronic resources to the creators of those, etc. Digitalization is aimed at training professionals who are guaranteed to be in demand in the labor market, will easily and freely use mobile and Internet technologies, as well as will be focused on lifelong learning (training) by means of digital technology.

It should be noted that informatization of education has created the ground for the transition to a new level - the level of digitalization. However, the digital environment requires from teachers a different mentality, a different perception of the world, completely different approaches and forms of work with their learners. Educators become not only a knowledge carriers that they share with their learners, but also a leader in the digital world (Nikulina \& Starichenko, 2018, p. 107).

Therefore, the system of professional training of teachers and educators requires modernization. It is necessary to bring educational programs in line with the needs of the digital society, widely implement digital tools of educational activities and fully integrate them into the educational and information environment of educational institutions, provide with the opportunities of lifelong learning for middle-aged and older generation at a convenient time and place. Digital literacy of educators and scientists as the ability to create and apply content using digital technologies, including computer programming skills, skills for information search and exchange, communication (Nikulina \& Starichenko, 2018, p. 111), is, to date, one of the most important issues.

Today there is no unambiguous interpretation of the concept of "digital pedagogy". Digital pedagogy is understood as the use of electronic elements in the educational process in order to enhance and change the educational experience (Kovalchuk \& Podolskaya, 2018, p. 523). V. Bykov and M. Leshchenko define digital pedagogy as a science of patterns transmission and perception of educational experience that occurs in physical and virtual realities through the use of information and communication technologies. According to L. Khutorska, the nature of information pedagogy is complex and belongs to different sciences, and information pedagogy itself should be considered as a theory of obtaining, transforming, transmitting and assimilating information in the educational process (Kovalchuk \& Podolskaya, 2018, p. 524). Scientists unanimously support the need for further development of pedagogical science itself, as digital technologies in the modern world should be considered not only as a learning tool, but also a new tool for creating a new educational environment with new opportunities and applications.

The modern child discovers the world not only directly through knowledge of the surrounding reality or through education in an educational institution and family influence, but also indirectly through information and communication tools, including a smartphone. This situation determines the features and specifics of education, upbringing and development of the child in the digital space, requires rethinking the content of key pedagogical categories, established educational technologies, forms and methods of teaching, changes in educational policy and established methodological practices both at school and educational system levels, and family as the primary institution of education.

The development of the content of digital pedagogy as a component of pedagogical science requires the joint and rapid work of scientists and practitioners.

In this paper, we formulated problematic issues that, in our opinion, are of primary 
attention and the development of which is based on the studied and generalized global trends in civilization in the context of digitalization processes, as the problems of digitalization of society, including education, are global and common to all countries.

Firstly, it is necessary to reveal the challenges of the digital society to the education system, which necessitate the following: complementing traditional pedagogy with digital pedagogy as a response to the global crisis; understanding what is the digitalization of education - a need or a temporary compulsory measure; elaboration of a strategy for the formation of content selectivity in children and youth in the conditions of educational digital intensive; counteraction to the means of technological and marketing destruction of basic values; developing a critical attitude to the media of digital influences; determining the specifics of the activities and activities of the subjects of the pedagogical process as a trend of digitalization of education.

Secondly, digital transformations that take place in didactics need to be understood. In particular, this applies to the didactic foundations of the learning process in the context of digitalization of education; didactic features of the digital learning process; the process of learning using digital technologies; specifying the determinants of the education content and the principles of its structuring for the digital educational process; methods and means of digital learning; forms of organization and modern technologies of digital learning; measuring students' learning achievements through digital technologies. In the context of digitalization of education, there is a growing interest in blended learning, issues of risks associated with the use of digital technologies in the educational process, organization of the digital educational process, establishing a list of important for society and education digital technologies (cloud, cognitive, big data technologies, etc.)

Thirdly, considerable attention needs to be paid to defining the conceptual foundations and technologies of educating children and youth in the digital space. In solving this complex problem, it is necessary, in our opinion, to pay attention to the following aspects: determining the educational potential of the digital space; picture of the world and offline primacy of attitudes to life; positivity of prospects of technological development and technology of educational action; methods of education in the digital space; digital educational environment; ways to recognize and protect a child from cyber-bullying; digital world and physical preservation. mental, social, and spiritual health of children and youth; partnership of parents and educators to prevent the negative effects of the digital environment on children and youth; inclusive education in the context of digitalization of education.

Fourthly, defining the essence and features of pedagogical activity in the conditions of digital education. In particular, we need to develop the following issues: the framework and content of pedagogical activity; digital pedagogical competence of the educator; e and self-analysis of pedagogical activity in the digital environment; educator's self-development and self-improvement through digital technologies; pedagogical interaction and pedagogical communication in digital education.

These issues systematically cover the most acute problems of organizing the educational process in the digital environment and ensuring its quality.

The answers to them actually constitute the content of digital pedagogy, which should be considered as a component of pedagogical science, which takes into account and is a response to the technological development of society.

\section{New dimension of education is the education of children and youth in the digital environment.}

The staff of the Institute of Problems of Education of the National Academy of Educational Sciences of Ukraine together with the Advisory Council on Digital Education and Pedagogy 
developed and discussed with educators the Concept of education of children and youth in the digital environment, which is a worldview of the modern idea of the process of education in the digital world and is represented by a system of scientifically substantiated provisions that identify societal challenges and strategic goals of education of children and youth in the conditions of digital reality.

The purpose of the Concept is to identify the leading ideas and principles of educating children and youth in the digital environment. The social significance of the Concept lies in the coherence of educational influences on children and youth in the digital environment; consolidating the efforts of the state, education and the family, the real sector of the economy to create a safe and conducive to the personal development of the child digital space.

It should be emphasized that the Concept is based on the main provisions of the Laws of Ukraine "On Education”, “On Complete General Secondary Education”, “On Child Protection”, Council of Europe Recommendations on Cooperation between Law Enforcement Bodies and Internet Service Providers in Combating Cybercrime, Guidelines Human Rights for Internet Service Providers (Council of Europe and EuroISPA) and the Guiding Principles on Human Rights for Online Game Providers (Council of Europe and ISFE), Concept for Implementing Public Policy in General Secondary Education Reform "New Ukrainian School” until 2029.

The Concept outlines the problems of raising children and youth in the digital space. The need to protect the child from cyberbullying is emphasized; counteraction to the means of technological and marketing destruction of basic values; development of digital competence of pedagogical staff; developing children and youth's values and content selectivity skills; preservation of physical, mental, social, spiritual health of children and youth; use of healthpreserving potential of family media education; fostering a culture of behaviour of children and youth in the digital educational space; partnership of parents and educators to prevent the negative effects of the digital environment on children and youth; scientific and methodological support for the education of children and youth in the digital space. The risks associated with the implementation of the Concept are described.

The structure of the Concept contains three main sections. The first section - "A new dimension of education - taking into account digital reality" - examines the educational potential of digital environment, the principles of education of children and youth under its conditions, developing the world and offline primacy in attitudes to life, the relationship of positive prospects for technological development and educational action.

The second section - "Children and youth in the digital environment: educational challenges" - highlights the problems of children and youth they face, namely the preschool child in the digital space: objective reality or necessity; digital environment in primary school students life; educational impact of digital environment on adolescents and high school students; digital internationalization in the education of students; cyberbullying: ways to recognize and protect a child; counteraction to the means of technological and marketing destruction of basic values, etc.

The third section - "Strategic directions of education of children and youth in the digital environment" - considers the following problems: digital educational environment of the educational institution; digital competence of educators; communication in the conditions of digital intensity: developing children and youth's content selectivity; digital world and preservation of physical, mental, social and spiritual health of children and youth; fostering the culture of behavior of children and youth in the digital educational environment; virtual art education; educational potential of out-of-school educational institutions in the conditions of digitalization; interaction of social institutions in the education of children and youth in the digital educational environment; healthy family media education: media digital diet and positive development; partnership of parents and educators to prevent the negative effects of 
the digital environment on children and youth; scientific and methodological support for the education of children and youth in the digital space; educational criteria and monitoring the quality of education in the digital educational environment.

The Concept also presents the risks associated with its implementation, the legal and managerial prerequisites for implementation, funding and expected results.

The development of the Concept allowed not only to identify problems in the education of children and youth in the digital space, but also to outline fundamentally new forms, methods and technologies of education in the digital environment.

\section{CONCLUSIONS}

Thus, we can say that the digital world has become the reality where happens the life of the modern human. The need for people of all ages to adapt to new technologies of the digital environment activates the educational paradigm of lifelong learning as a form of improving their digital competence, self-development, professional and life self-realization. The mission of modern education is to help everyone feel comfortable in the digital society.

Digitalization of education requires the definition of pedagogical priorities in the transformation of the essential positions of pedagogical science, revision of forms, methods, tools and technologies of teaching, education and development of the learner.

The content of fundamental provisions, categories and concepts of traditional pedagogy regarding the organization of the educational process in the digital space needs to be reconsidered. It is time to develop the conceptual provisions of digital pedagogy, and digital didactics in particular.

The conceptual vision of the problems of the organization of educational influence on children and youth in the digital environment and the means of their solution acquires importance.

The digitalization of education requires the collaboration of scientists and practitioners of pedagogical and psychological sciences, digital technology specialists to find interdisciplinary solutions of modern problems of organization of the digital educational process.

\section{REFERENCES}

Kovalchuk, V. I. \& Podolska, I. S. (2018). Zastosuvannia tsyfrovoi pedahohiky v pidhotovtsi maibutnikh fakhivtsiv sfery pidpryiemnytstva. Young Scientist, 5(57), 523-526.

Nikulina, T. V. \& Starichenko, E. B. (2018). Informatizatsiya i tsifrovizatsiya obrazovaniya: ponyatiya, tekhnologii, upravlenie. Pedagogical Education in Russia, 8, 107-113.

Strekalova, N. B. (2019). Riski vnedreniya tsifrovykh tekhnologiy v obrazovanii. Vestnik of Samara University. History, Pedagogics, Philology, 25(2), 84-88.

Sysoieva, S. O. (2014). Tvorchij rozvitok fakhivciv v umovakh magistraturi. TOV «Vydavnyche pidpryiemstvo «EDELVEIS».

Taleb, N. N. (2019). Chernyj lebed'. Pod znakom nepredskazuemosti (2 nd ed., O. Kapanadze et al. Trans.). KoLibri, Azbuka-Attikus.

Zenkov, A. R. (2020). Tsifrovizatsiya obrazovaniya: napravleniya, vozmozhnosti, riski. Proceedings of Voronezh State University. Series: Problems of higher education, 1, 52-55. 